\title{
Retinoblastoma cT4d TNM Finding v7
}

National Cancer Institute

\section{Source}

National Cancer Institute. Retinoblastoma CT 4d TNM Finding v7. NCI Thesaurus. Code C88768.

Intracranial extension past chiasm. (from AJCC 7th Ed.) 